\title{
Analysis of Metaphor and Comparison in "Metaphor-structure
}

\author{
"Sentences \\ Meifang Yang \\ Wuhan City Vocational College \\ Address: No.10 West Yezhihu Road, Hongshan District, Wuhan, Zip Code: 430064
}

Keywords: Metaphor Structure Sentences; Comparison; Analogy; Similarity; Equivalence.

\begin{abstract}
Like" and "as if" are two words that are frequently used. In order to make it convenient, this paper will use "metaphor-structure sentence" to refer to sentences with "like" or "as if" and represents them with "A is like B". In "metaphor-structure" sentences, the meanings of "like" and "as if" are very flexible because these two words can refer to analogy, comparison, speculation, indication and instance, etc. Herein, the most difficult to discriminate between is comparison and analogy. This paper proposes "three see" standard to discriminate analogy and comparison of "metaphor structure" sentences: to see whether A and B in "metaphor structure" sentences are different essentially; to see whether A and B in "metaphor structure" sentences are similar; and to see whether A and B in "metaphor structure" sentences are equivalent.
\end{abstract}

\section{Introduction}

"Like" and "as if" are two words that are frequently used. In order to make it convenient, this paper will use "metaphor-structure sentence" to refer to sentences with "like" or "as if" and represents them with "A is like B".

According to preliminary statistics, there are altogether 353 texts in the compulsory education curriculum standard textbook "Chinese" of the People's Education Publishing House, herein, two words are used in more than 180 texts. It is slightly less in the low section but more in the upper section. For example, among the 32 texts of the first textbook for grade four, these two words can be found in 20 of them, and among the 28 texts of the first textbook for grade six, they can be found in 19 of them. They can be seen more frequently in textbooks of grade seven and grade nine. Except poems and classical Chinese, nearly every essay in textbooks contains "metaphor structure" sentences.

In "metaphor structure" sentences, "like" and "as if" have flexible meanings and they can refer to analogy, comparison, speculation, indication and instance, etc. When I attend Chinese classes at primary and secondary schools, I often encounter mistakes or debates about judging the ideographic meaning of "metaphor structure" sentences

Comparison is a logical method and metaphor is a rhetorical method, and they belong to two different ranges, so they should go their respective way without interfering with each other. However, in language practice, especially in "metaphor-structure" sentences, their identities are usually not clear, thus causing confusion. 
Mr. Liu Dawei said, "Comparison is a logical method, metaphor is a language--strictly speaking it should be a complete speech acts, they were not in a comparable level. Any parable contains a comparison, without comparison, body, metaphor and the relationships between them it is impossible to determine." (1)

In view of this, comparisons and metaphors belong to different categories, but has a very close relationship: no comparison, analogy does not hold. So, how to tell: "a is like b" is a pure comparison or contains a comparison of analogy?

The author believes that it can be measured from the three following perspectives.

\section{Whether A and B are Essentially Different in "Metaphor-Structure" Sentences}

It is said in "Modern Chinese" edited by Huang Borong and Liao Xudong that: "For example, the parable is something called 'the body', he used the analogy of things called 'Vehicles', and contact between the two words is called 'metaphor word'. Tenor and the vehicle body must be two distinct things, the use of certain similarities between them to fight for example, constitutes a metaphor. "(2)

Mr. Chen Wangdao stresses in "On Rhetoric" that "Metaphor and the metaphor of two things has to be extremely different in its whole." (3)

Qian Zhongshu in his notes in the great work of Guan zhui bian said: "where Yu will make non-class", "metaphor in a different class as a class." (4)

Here, "different nature", "extremely different on the whole" and "different categories" refer to that body and vehicle must be essentially different two things simply understood as "different class". Therefore, we can draw the following conclusion: the judgment "a $b$ " is more figurative, simplest method is: first of all, to see where A and B are not "distinct". If they are not "different", but rather "essentially the same", is rather more; if they are indeed "nature" is likely to be, or it may be, further analysis was combined with the following conditions. For example:

He likes to work and his team, so I should do so like him.

"6 I Choose Me" in the First book for Grade Two, People's Education Press

(2) I'm not like a dancer, adept to praise their hand gestures, how "nature color."

"19 Watch Dance" in the Second Book for Grade Seven, People's Education Press

(3) Now you see the star fruit, carambola as you usually see it?

"11 Draw Carembola" in the second book for Grade Three, People's Education Press

(4) Some dinosaurs were bipedal running like their ancestors, some dinosaurs were quadrupedal walking.

"31 Dinosaurs Flying to the Sky" in the first book for Grade Four, People's

(5) He also carefully selected materials like the past, not sloppy at all.

"6 Wanian Nao" in the second book for Grade Four, People's Education Press

(6) One day, as usual, I went with my father to the nearby small islands in the lake fishing.

"13 Enlightenment on Fishing" in the first book for Grade Five, People's Education Press

(6) Look, he looks like his mother: red mouth, red feet and blue and grey fur without round white dots like pearls at the back.

"16 Pearl Bird" in the first book for Grade Five, People's Education Press

(8) The fruits of it buried in the ground, unlike peaches, pomegranates, apples, green red fruits high up in the branches, so that people at a heart of love.

"15 Peanuts" in the first book for Grade Five, People's Education Press

(9) Its fat, whole body like a fluffy balls. 
"16 Pearl Bird" in the first book for Grade Five, People's Education Press

"I" and "he" in case (1) are of the same nature, specific of people, and two people have common features: love labor, love collective, this is through compared looking for same points; cases $b$ in the of "I" and "Dancer" are is people, just two-phase compared, a "layman" a "expert" just, this is through compared highlight different points; cases $c$ in the front of Carambola peace Shi see of Carambola are is specific of Carambola, just due to observation angle different, rendering of State different just; case (4) in the evolution of dinosaur and they of ancestors nature same , And has common features: two foot run; case (5) in the today of he and past of he is same personal, and also is as seriously selected material, little not sloppy, this is through compared looking for same points; case (6) services in the "one day" and "always" appeared of case same, that "I followed father to near Lake in the of small island up fishing"; case (7) in the chicks and it of mother is are is bird, nature same, and features has with has different, this is through compared find same points and different points. The seven "sentence" A and B are not in "two things of a different nature", nor with Mr. Chen Wang-DAO said, "It must be very different in its overall" requirement, therefore here only, no metaphor.

In case (8), "peach, pomegranate, Apple" is a fruit, peanuts do not fall into this category, so this "sentence" of a, b is "very different in its overall", are essentially different. In case (9), chicks "whole body" and "loose balls" are "two things of a different nature". However, these two sentences in the "like" or "as if" was said or are parables? Also have to take into account the conditions: a, b has similarity.

\section{See Whether There are Similarities between A and B in "Metaphor Structure" Sentences}

Mr. Chen Wangdao wrote in "On Origin of Rhetoric" that "Metaphor and analogy, two things must have is extremely similar."

It is said in "Modern Chinese" edited by Huang Borong and Liao Xudong that: "For example, the parable is something called 'the body', he used the analogy of things called 'Vehicles', and contact between the two words is called 'metaphor word'.

Mr. Chen Changning said: "the similarities were known as the parable of the soul, is the basis of metaphor. "" Similarities is a bridge between body and a tenor."

Mr. Liu Dawei said: "Figurative use is a similarity relation between two objects."

Comprehensive analysis of these remarkable assertion, you could say: the analogy is similar to A, $\mathrm{B}$, rather than the similarities or differences. If you combine this with first, you can say: "the sentence" If $\mathrm{a}, \mathrm{b}$ are not only in different things, and have similarities and also meet these two conditions, it is possible to be, otherwise it is not a metaphor.

Previous analysis of case (8) "peach, pomegranate, Apple" and groundnut is "very different in its overall". What about whether there are similarities between them? And see: author took fell peanut with peach, and pomegranate, and apple for compared, to highlight they of different points (fell peanut of fruit buried in field, mature has, people also see missing; peach, and pomegranate, and Apple is put red green of fruit high to hanging in branches Shang, whether mature, an eye on can saw--makes people a see on health love of heart), and not highlight they of similar points, so here of "like" said compared, and not said metaphor.

In case (9), the chicks' "whole body" and "fluffy balls child "belongs" in nature are two different things, "" fluffy balls child ", not only round, but also soft, very soft, feels very comfortable, it looks very seductive, very cute overall. Nestling "whole body" what would happen? The authors did not 
say so, just tell the reader "The whole body is like a fluffy ball child", whereby the reader can imagine cute chicks posture of: a round body, the dough fluff ... Therefore, are similar between them, and not the same or different. So, for example, in the use of metaphor in case (9). Another example:

(10) Entering the Hall, standing on a bird's eye view high, pits of Terra-Cotta Warriors line by line, column, columns, is in order, into a huge rectangular arrays, really like the Emperor in command of an army of fighting to victory that year.

“19 Qin Terracotta Warriors and Horses" in the first book for Grade Four, People's Education Press

(11) Mr. Ye shook hands with me upon seeing me just like seeing a good figure, suddenly shortening the distance between us.

"26 Those Green Ivy" in the first book for Grade Four, People's Education Press

(12) Not only for the village village is just like our village, planted many trees last year.

"18 A Youth's Diary · Three Old Ginkgo Trees" in the first book for Grade Eight, Hubei Education Press

In case (10), terracotta warriors and horses arranged in a rectangular array and when command of the army of Qin Shi Huang is a different thing, but the relationship between them is not "similar", but the same. Simulation of Qin terracotta warriors and horses, because the individual is, the entire hall layout and simulation, so not a metaphor. It's like "this plastic roses like real roses," who would believe that this is a metaphor sentence?

In case (11), Ye meet with adults are generally required to shake hands, this is etiquette, see "I" also "shook", both of which are the same, not "like", so there is no metaphor.

In case (12), "Our village" planted a lot of trees, "the village" has also planted many trees, which is comparing the two in order to look for similarities (planted a lot of trees), rather than the similarities, and therefore is not a metaphor.

\section{See Whether A and B are Equivalent in "Metaphor Structure" Sentences}

So-called equivalent dictionary explanation is: (different) equivalent to the numeric value or value. Mr Cui Yingxian said: "comparison of A between B, is the basis of establishing relationship of equality. Saying 'A is as high as B (length, weight, thickness, black ...)', in theory, can be converted to ' $\mathrm{B}$ as high as A (length, weight, thickness, black ...)'. Application cannot be converted or limit such freedom of subject and object in the expression; qualitative judgement or whether in the form of expressing semantics are not responsible. Analogy of A and B is not the same, and are usually shown as 'yitouchen', which means that the expression of ideas are not equal between the two. "If you compare the two sides met on the premise are equivalent, the analogy is not equivalent."

Sample (1) is compared, not as metaphor, "I'm going to love labor, like him, concerned about the collective", without taking into account the main object, saying "e will like me love labor, collective concern" is perfectly possible.

Similarly, sample(7) "how like its mother: black-red-foot, gray-blue hair" without considering the factor of subject and object, saying "its mother how like it: black-red-foot, gray-blue hair" is also acceptable.

We'll take a look at the following three"Metaphor-structure" sentences:

(13) His children as high as desks.

(14) His children as high as a door of that little tree.

(15) His children as high as a mountain. 
In cases (13) and (14), "like" can understanding for "equivalent", and "almost", respectively can said into "he children with desks almost high", and "he children with door of that tree small tree almost high", here of "he children" and "desks", and "door of that tree small tree" is equal of relationship, is equivalent of, theory before and after location completely can swap. Therefore, these two are compared.

In case (15) "his children" and "mountains" are not equivalent, whose children have "big mountain" so high? Do not say "big mountain", is "the hill" there were dozens of meters high, right? Don't say baby, Guinness world record tallest natural persons is less than three meters. Where a, b are clearly very obvious "yitouchen". If A and B reversed, as "mountains as high as his children", it is also called "the mountain"? "His children" and "mountain" belongs "to two things of a different nature", has a similar relationship between the two: tall, well-built. Therefore, use an analogy (is appropriate, another story).

In view of this, we can in accordance with part A and B is equivalent to judge "sentence" is a comparison or a metaphor.

To sum up, judging a "sentence" was said or a metaphor, can be considered from three aspects above. In practice, however, cannot be separated from the above three aspects, analyses in isolation, but should be linked the three, synthetic judgments from a different perspective, this is more of a science. For example:

(16) Mountain was about to jump like a frog.

The 3rd Book 27 Clear Lake

(17) After that, the girl suddenly disappeared, as she suddenly came to.

The 10th Book 10 What is happiness

(18) The milky way like a flat wheel, more than 80,000 light years in diameter, and spin like a wheel, so the star at different speeds around the Center in mob.

— The second book for Grade8 of the Hubei education press 8 Lying morning glory Vega

In case (16), the words "Rock" than a "jumping frog", "rocks" and "frogs" are "two things of a different nature", but there are similarities, that is the rocks here, its shape and the frog and frog that cute look. Wherein, A and B do not equal, if it is turned upside down, as "a frog rocks like there was about to jump up", it would have been confusing. Therefore, use an analogy. Authors, readers and recycling of imagination, empowerment of mountain life, vitality, and written in such lovely fresh immovable rocks, adds a lot of charm.

In case (17), girl, "vanished" and "descended" is different to the two States, but they have common characteristics, hurry and without leaving any traces. Between the two are not similar, but different. Meanwhile, regardless of if the sequence of events described in the factors, this "sentence" in the A and B reversed, saying "the girl suddenly came, as she vanished" is also acceptable. A is equal to B in this sentence. Therefore, it can be concluded that: in this sentence only and there is no metaphor.

In case (18), both use "like" previous emphasis on appearance and a focus on sport. After the compression is "milky way like a wheel", and "Galaxy" with "wheels", are "two things of a different nature". The authors draw a comparison between the two, in order to highlight the similarities between them: similar in shape, are round; movements similar to, are built around a central "spin". But never the same, because the Galaxy is very big, "more than 80,000 light years in diameter", no way to see with the naked eye, and wheel size, according to network statistics, currently the largest diameter of the wheel is less than five meters, showing that this "are not equal between the two." Therefore, "like" metaphor. Authors take for example people familiar very familiar with wheels, 
easy reader by Association and established the basic concepts of the Milky Way Galaxy. This is a common description of the method.

In short, these three can be used as a "sentence" comparisons and metaphors in "touchstone", and by analogy to analyze "as if, like the words" sentence, judge said they or a metaphor.

\section{References}

[1]Huang Borong, Liao Xvdong. Modern Chinese [M]. Beijing: Higher Education Press, 2007:184

[2]Chen Wangdao. On Original of Rhetoric [M] Shanghai: Fudan University Press, 2008:75

[3]Qian Zhongshu, Guan Zhui [Z]: Beijing: Zhonghua Book Company, 1980:75 